\title{
Dealing with Challenges in Teaching \& Learning Mathematics in Flipped Classroom Model in Pandemic Era
}

\author{
Agus Sofian Eka Hidayat ${ }^{1,{ }^{*}}$ Wakhid Fitri Albar $^{2}$ Wihdati Martalyna $^{3}$ \\ ${ }^{1}$ Actuarial Study Program, President University, Indonesia \\ ${ }^{2}$ Mathematics Department, Universitas Gadjah Mada, Indonesia \\ ${ }^{3}$ Mathematics Education Program, Pekalongan State Islamic Institute, Indonesia \\ *Corresponding author. Email: agus.eka@president.ac.id
}

\begin{abstract}
The existence of technology in teaching and learning processes has changed the way how teachers transfer their knowledge to their students. Moreover, pandemic covid-19 has forced the use of technology in learning. The existence of flipped classrooms has given positive effects towards both learning effectiveness in understanding the basic concept, attractive learning, student achievement also collaborative learning among students. Flipped classrooms, however, have some challenges in an actual class application. Therefore, this article is intended to explore the various challenges of teaching and learning mathematics in flipped classroom model in the pandemic era. The teachers who commonly use traditional teaching as their method preference find some problems regarding how to manage and design the flipped classroom model in their teaching practice. To learn more about the idea of flipped classroom design, teachers should enhance their knowledge through training or collaborative study with professionals or experts in flipped classrooms. This is vital because it helps the teacher set up their classroom properly. Furthermore, we managed to implement the flipped classroom, then provided the data in the form of descriptive analysis.
\end{abstract}

Keywords: Flipped Classroom, Mathematics, Pandemic, Senior High School.

\section{INTRODUCTION}

The existence of technology in teaching and learning processes has changed the way how teachers transfer their knowledge to their students. Flipped classroom model is one of the learning models which uses the implementation of technology such as video, YouTube, online website, podcast, or Moodle as primary resources for students to learn outside the classroom. According to [11], the implementation of flipped classrooms is gaining more popularity across the college. Moreover, it also has been conducted in several schools in developed countries. This method of learning is not only used in a particular subject requiring communicative skill, such as language learning, but also subjects dealing with numerical learning, for instance, economics [20], chemistry [21], statistics, and mathematics ([11], [26]). The existence of flipped classroom has given positive effects towards attractive learning, student achievement, collaborative learning among student, and learning effectiveness in understanding the basic concept ([16], [19], [24]).

Flipped classrooms are then believed as one of the new methodologies of teaching which promotes the idea of students as self-learner and technology as a key point to conduct education and learning processes. Flipped classrooms, however, has some challenges in an actual class application. The teachers who commonly use traditional teaching as their method preference find some problems regarding how to manage and design the flipped classroom model in their teaching practice [10]. Besides teachers, students also have some issues of technicality when being taught in flipped classroom design ([2],[18]), which are demotivation [25], lack of understanding [10] and cooperation during in-class and out-class activity [12]. Nevertheless, these emergent issues are only revealed to be discussed by the existing literature, without much attention given to the possible solutions for resolving the problems. It is to contend that these challenges, we believe, are not well addressed by the limited research. Thus, we are keen to investigate the 
challenges of implementing flipped classroom design with more in-depth discussions that do not only locate the problems but also suggest the possible solutions for the emergent issues of the aforementioned teaching design.

The pandemic era has enforced schools to have full online learnings. The covid19 pandemic has changed the habits and even the culture of human beings. A clean lifestyle and the use of face maskers have been campaigned by the Indonesian Government. One of the impactful consequences is that people have to make distance one to another by around 2 meters, therefore conducting offline learning such as classical learning in a room is prohibited. It resulted that school learning has to be fully conducted online. It is a challenge for the schools, teachers, and students since they were not used to having online classes throughout a semester. Some schools have limited facilities for online learning and adapting to this condition is mandatory.

In this essay, we will explore the challenges of the implementation of flipped classrooms. We argue that there are three major challenges which must be discussed: teacher capability, student demotivation and engagement, and student achievement. After critically analyzing the emergent issues, we will present possible solutions for the problems, specifically addressed to teachers whose classroom is equipped with flipped classroom activities. The essay is expected to give significant exposure which informs teachers to be fully prepared when teaching with the flipped classroom design, as its beneficial potentials come along with drawbacks if not well taken care of. We also manage to implement flipped classrooms during this covid19 era at the first-year science classes of SMAN (State Senior High School) 1 Slawi based on our explorations of flipped-classroom challenges. The results were quite surprising regarding various handicaps of the situation.

\section{FLIPPED CLASSROOM: DEFINITION, BENEFITS, AND PROBLEMS}

There are various definitions which are used to define what the flipped classroom is. In the very simplistic definition, a flipped classroom is a classroom design where the face-to-face meetings are combined with meetings in digital worlds: websites, videos, podcasts, and any other internet-based forums. Not only does flipped classroom design focus on differentiated types of communication, but it also focuses on quality of learning; it transforms the idea of learning from teacher-centered to student-centered foci. The flipped classroom, as known as the inverted classroom, replaces 'oldfashioned' lectures in a traditional classroom with the concept of active learning through practice and group work. According to Petrolio [19] and Love [11], in a flipped classroom student learn the initial course concepts (prior knowledge) outside of the classroom while class activity is more focused on problem-based learning through individual or group discussion. The group learning space or personal learning space in-class activity is expected to promote a dynamic and interactive environment where the educators guide students as they apply concepts and engage creatively in the subject matter.

Flipped classrooms allow a variety of mediums for learning to take place, as in the resources of a video podcast, YouTube, Website, Moodle or Khan Academy or a media made by their tutor. In some cases, teachers might make their personal videos or lesson materials and uploaded them online, or they can use online resources which are available and accessible to their student. Every learning resource is expected to give the students more understanding of the topic and enhancement of their knowledge before doing the in-class activity. Hence, the idea of flipped learning is a provision to achieve mastery of subjects as the students are more able to self-pace their learning.

The benefit of flipped classroom design varies and has been reported by some researches (see [6], [19]). Firstly, it decreases the time of student taking note and focuses on problem-solving in-class activity [19]. Secondly, the students can view the online materials on their schedule as frequently as needed, since the materials are very flexible to use. Fulton [6] strengthens this as he professes that flipped classroom gives teachers' better insight into student difficulties and learning styles, fosters the effectiveness and creativity of teachers to use the time, also improves student achievement, interest, and engagement.

After discussing the benefits of implementing a flipped classroom design, it is to concur that the implementation has problems notwithstanding. In flipped classroom design, teachers and students may encounter issues which most likely inhibit the learning from excelling to successful outcomes. The report from both Petrilio [19] and Kensington-Miller et al. [9] reveals that flipped classroom may not be suitable for every teacher, every student, and in every situation. He claims that the condition can happen due to the inability of students or teachers to engage with the variety of components such as media, assessment, and collaborative learning. Thus, it is crucial to identify the issues from both teachers' and students' perspectives in the actual implementation of flipped classrooms.

\section{PROBLEMS INSIDE FLIPPED CLASSROOM IMPLEMENTATION}

In this section, we will discuss the issues in flipped classroom design both from teacher and student perspectives, based on research finding from the implementation in mathematics classrooms. 


\subsection{Problems from Teachers' Perspectives}

A teacher can be symbolized as a pilot who controls the airplane or a machinist with a train. They are the one who has the responsibility to monitor and determine how fast the speed or which lane must be selected to achieve the goal to arrive at the expected destination. A teacher in a flipped classroom is like either pilot or a machinist who has the responsibility to assist the student in the teaching and learning process. They have a responsibility to manage their class.

A teacher is the one who decides what kind of resources are to use in the flipped classroom model, what assessments are valid and reliable to assess the student capability in the flipped classroom model, and what kind of activity is needed to encourage the student to be participative in collaborative learning. Unfortunately, teachers are oftentimes discouraged and, arguably, incompetent to face the demand of collaborative-learning management in the flipped classroom as they are unable to manage their class [10]. Besides lacking skills in classroom management, the capability of teachers to deal with media is also an influential inhibiting factor. Teachers may experience some difficulties to select and create materials such as video podcasts because their capabilities are often marginal and require an enormous amount of time ([8], [18]).

Therefore, it is to note that the teachers' knowledge and courage are very crucial in implementing flipped classroom design. Teachers have to master both theories and practical knowledge of the design they are using, because both types of the knowledge may ultimately be a determining factor to either success or failure of the flipped classroom ([1], [3], [24]). Moreover, the practicality aspect also needs to be enhanced as the concrete manifestation of the application of a theory. In conclusion, it is prominent for the teachers to completely acquire knowledge about the theories and practicality of flipped classroom design and feel encouraged to control the students more strategically and confidently.

\subsection{Issue from Students' Perspectives}

Students as the center of learning in flipped classroom experience a different atmosphere of learning in the flipped classroom compared to the traditional classroom. Flipped classroom design provides independence for learners to learn outside of the classroom by understanding the material from online resources given by a teacher. The students are required to compete with the technology used by their teacher to support the learning, for instance, Moodle, YouTube, ALEKS, Academic Khan, Video Podcast, and many others. However, the capabilities of the student to perform with technology is different; some students still have a problem to access technology which leads to stressfulness among the students [2]. This condition needs to be considered as one of the problems which need to be figured out by the teachers before adopting the flipped classroom

On one hand, flexibility in a time of learning, especially out-class activity, makes it easier for students to repeat the learning process to enhance their knowledge before entering the class. According to Petrillo [19], the students in mathematics class often use videos as their learning materials, and more than $45 \backslash \%$ of the students are shown to have watched the videos more than one times. On the other hand, Wilson [27] and Harried and Schiller [8] emphasize that there is a tendency that students do not regularly read a textbook or watch video assigned by the teachers, hence being unprepared for the class activity. Student demotivation is influenced by the type of resources or lack of treatments that force the student to keep in touch with out-class activity, and it can be associated with the factors that influenced how students react with a condition in flipped classroom design.

Not only does student motivation affect how the students learn by themselves in out-class activity, but it also affects how they behave in class. Classroom activity is designed as a forum discussion rather than lecturing class, where the students are working with peers to solve problems given by their teacher according to what they have learned before the class begins. The group discussion is expected to become a place where students can share their understanding with others, correct their mistakes from prior learning, and try to have clarification from the teacher regarding what they believe and what they assume to be false about the topic material. Group discussion can be valid as long as every student is involved and active in the group. Unfortunately, not all students can engage with this condition as Marco et al. [12] discusses, that passive attitude and engagement in classroom tasks are inevitable. Meanwhile, Van Seters et al. [25] find that students who have achieved highly are less likely to be willing to contribute to discussions with their fellow students. Cases explained by Marco commonly happen in an actual classroom; for example, in group discussions, some students may become a major focus of the group because they are more skilled or knowledgeable rather than the others, so they are more active compared to the others. However in the case brought by Van Seters, if the expert students are kept in silence and not trying to share their knowledge in solving the problem, the group discussions tend to be full of silence and meaninglessness towards the classroom activity. Due to both of the considerations, teachers should undertake the problems by creating a concept of group discussions which can encourage every student to involve.

In conclusion, what is needed to be considered the most in flipped classroom design is how it can achieve the goal to make students have a better understanding and 
achieve a significant result of learning. Although some research has explained the positive sides of flipped classroom design, the potential challenges in the actual classroom teaching and learning process should be discussed more to discern the best options to address the problem. The next discussion will focus on how to address the major issues in the flipped classroom, which are earlier discussed.

\section{DEALING WITH POTENTIAL ISSUE IN FLIPPED CLASSROOM}

In this section, we will discuss the issues in flipped classroom design by reflecting on the key factors in both teacher and student perspectives. We will take a look at the critical improvement of teachers in flipped classroom design through training and teacher collaborations. We will also specifically discuss assessments and quizzes which are necessary to make students more prepared in learning, as well as the concept of group leader rotation as one of the possible solutions to address less student participation in group discussion.

\subsection{Teacher Pedagogy Improvement}

Marshall [13] points out in her model of Flipped Learning that one key role for teachers is to "lead from behind." In other words, the teacher engages in "observation, feedback, and assessment" during class.

Teachers have been identified as failed to manage their class such as promoting collaborative activity [10], choosing the appropriate material for students [18] and using proper assessment. This problem appears because the teacher was lack of experience in teaching and learning using flipped classroom design. In fact, flipped classroom design demands professional and skillful educators because they are needed to determine when and how to shift direct instruction from group to individual learning space and how to maximize the face-to-face time between teachers and student [7]. Hence, we need to guarantee that teachers in the flipped classroom become professionals to anticipate the issue above.

There are two treatments that can be used to professionally develop the teachers in flipped classroom design. Firstly, according to $\mathrm{Ng}$ [18] teachers in a flipped classroom need to be educated first as well as trained to master each concept of the flipped classroom. By teaching the teachers about the flipped classroom, it will give them an explanation about how to construct flipped classroom properly and utilize training as a supplement to improve their skill. Secondly, the idea of teacher collaboration which is mentioned by Petrilio [19], can be one optional choice to improve teacher knowledge. Cooperation between a teacher with some expert in a flipped classroom or team teaching can give advantages to help teachers in designing the concept of learning or media. Under the supervision of an expert both in training or collaborative teaching, automatically the teachers will receive meaningful feedback which can be used to expand their professional skill and experience in flipped classroom design. Likewise, Muir and Geiger [17] believe that students feel more appreciative when a teacher uses their own video on flipped as it helps to build a sense of relatedness between student and teacher, which affect student motivation and engagement in a math course.

\subsection{Improvement of Student Engagement}

Active engagement of students in both inside and outside activity in a flipped classroom is very crucial. Teachers need to design the ideal method of a classroom for their students. The issue of disengagement of students must be well taken care of. The concern comes from Ash [1] who says just having students watch videos instead of listening to lectures doesn't guarantee that they will be more engaged in the learning. Instead, requiring students to take notes on the videos, ask questions about the videos, or engage in discussion about them will help ensure that they watch and absorb the material. Hence, teachers are required to design a type of learning which can increase student participation in the classroom.

Student engagement outside the classroom can be improved by making videos, written assignments, and/or online quizzes as a prerequisite prior to attending the class. We believe this treatment is significant to oblige the student to read or watch the content as it will help them to answer the problems. McClelland [14] explains that students must be able to acquire knowledge outside of the classroom in order to arrive prepared. If the student is not preparing themselves, it will cause a failure for the quiz or task assessment. Moreover, it is also justifiable to help students become more in hand with that activity because "scaffolds such as worksheets or quizzes are necessary to help students focus on the main ideas and assess what students learned from the homework videos" ([16] p.424). The result of the assessment or quiz adequately reflects a level of knowledge attained by the student. Furthermore, it shapes common misconception shared by groups of a student [26]. In the end, the implication of pre-assessment will help the teachers to review treatment which will be given in in-class activity.

If students accomplish the pre-learning assessment successfully, the teacher can continue to focus on group discussions. However, they can raise student understanding through class lecturing if the result beyond teacher expectation. Kirvan et al. [10] suggest teachers develop student achievement in out-class activity, where the student who failed to achieve pre-assessment standard were required to have a 15-minute re-teaching program before entering exploration group session. In this reteaching, a teacher not only has the responsibility to review what weaknesses performed by the student but also need to build student "self-awareness about the 
material through feedback and direction" [26], to avoid similar mistake happened in further. We argue this method is well enough to strengthen student ability, but it requires team teaching collaboration because of time limitation, which uncommonly happened in school classrooms but possible in higher education.

\subsection{Increasing Student Collaboration in Class Activity}

Kensington-Miller et al. [9] highlight that an educator must anticipate possibilities of their student to become passive in the group rather than passively taking a note. This situation indeed, to make sure the group discussion running very well, so students can share their understanding and solved it in a group. To handle the passiveness of a student in group discussion, we propose that teachers should use an idea of leader rotation in group discussion.

Although sometimes it may feel frightening to become a leader, there is some benefit that can take away. Firstly, they will experience the group and individual members, gain insight into the process, improve interpersonal competence, and transformational growth over time. Secondly, it can increase the understanding of challenges and reward if group leadership to make sure they will [23]. This situation also visible if it is implemented in classroom learning. When the teacher gives an opportunity for each student to become a leader in group discussion, they initially need to control their group and not keep silent. Moreover, Yamaguchi [28] explains "whereas one member emerged as math leaders, focusing on the calculations, other members emerged as social leaders, focusing on group cohesion (p.683)". The head of the group needs to open the debate and find the debate or similarity from the group discussion. Hence, student demotivation and less participation influenced by an unwillingness of talented students to share their knowledge or silence among group discussions will be covered simultaneously.

\section{IMPLEMENTATION OF FLIPPED CLASSROOM DURING PANDEMIC ERA}

During this covid19 pandemic, schools are wished to alter from offline classes to online classes. During these months, we managed to implement flipped classroom learning in some class in SMAN 1 Slawi (State Senior High School 1 Slawi). We implemented flipped classrooms for the subject of mathematics for science classes of the first year.

We made videos then upload the videos to YouTube before the meeting schedule. At the meeting schedule, students and the teacher are discussing via WhatsApp Group. After finishing the discussion, the students were asked to take notes from the videos and discussion in which they would scan or take pictures of the notes then upload it to the provided form. After that, the students would have to work on 2-3 tasks related to the materials. At the end of the first chapter, we conducted a test which would evaluate their learning up to this midterm semester. Surprisingly, with all the limitations, most of the students performed well on the test.

As mentioned in the previous chapters that it is better if the teachers managed to make their own videos, then upload them to some platform which is accessible by all students. We highlight the self-made videos by the teachers since the students would have successfully acknowledged that they had to work hard as their teachers did. YouTube was considered to be one of the most accessible video platforms. Samant [22] explains that YouTube EDU videos can be utilized for making wellinformed decisions for improving educational content and learning technologies. In the case of our classes, all students have smartphones and they have been familiar with YouTube. Therefore, by those considerations, we chose YouTube as the platform to upload the teacher's videos. From the views of YouTube, the teacher could analyze the success rate of their videos.

The classes were conducted in a WhatsApp group. A WhatsApp group was chosen for conducting discussion during the class since WhatsApp is common among all students and teachers. Thus, they did not need to take time for adapting. Dahdal [4] finds that the use of WhatsApp as part of course gradable assignments can contribute to active learning and enhance collaborative learning pre- and post-lectures. On the one hand, having a face-to-face discussion on virtual video conference apps such as Google Meet, Zoom, and Cisco Webex will have more advantages. On the other hand, regarding the students' conditions in which some of them did not have such facilities to join a video conference. Most of the students had limited internet access such as limited mobile data quota and internet signal qualities. Therefore, it was not possible for forcing to use video conferences for the classes. In spite of the limited conditions, students were found very active during the discussion in the WhatsApp group. They were actively answering the teacher's questions as well as proposing some questions to the teacher. The teacher began the class by giving a brief explanation and brainstorming questions to the students. The students immediately answered the questions, then the teacher confirmed their answers and gave follow-up questions, and then the teacher did not forget to give appreciation and rewards to the students. Some of the footage during the class discussion can be seen in the Figure 3.

After the class finished, the students were asked to take notes of today's learning. It has become obvious that note-taking in math classes is important in terms of the form and the process [5]. The notes had to be submitted in the form of pictures (.jpg/.jpeg) in the provided google form. This note will be evaluated to ensure whether they 
understood the learning. Besides, the students were also obliged to work on some tasks. The questions on the tasks were additional tools for evaluations. By taking notes tidily after classes, we believed that the students would experience the knowledge by themselves therefore they would gain precious experience of evaluating their understandings and of exercising for writing down what on their minds. The tasks would enhance their problemsolving skills. Hereby, we attach some of their notes and works of the tasks on the Figure 2 and Figure 3.

After finishing the first chapter, the teacher conducted a test to evaluate students' understanding throughout the learning of the first chapter. The test also evaluated the midterm semester. Even though all of the limitations that we had such as the new learning style for students which had never experienced full online learning and limited facilities for conducting online learning. The results of the test were surprisingly good. The class achieved 83 as their means and only 4 out of 36 students who did not pass 75 which is the minimal competence score. The lowest score is 60 and some students managed to get full scores which are 100. The standard deviation was 9.2 which means that the mean represents the class performance.

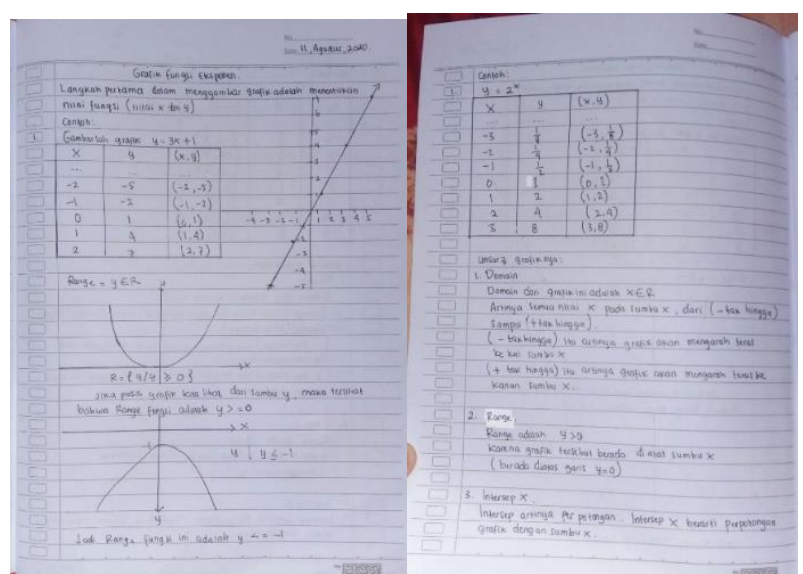

Figure 2. Student's notes.

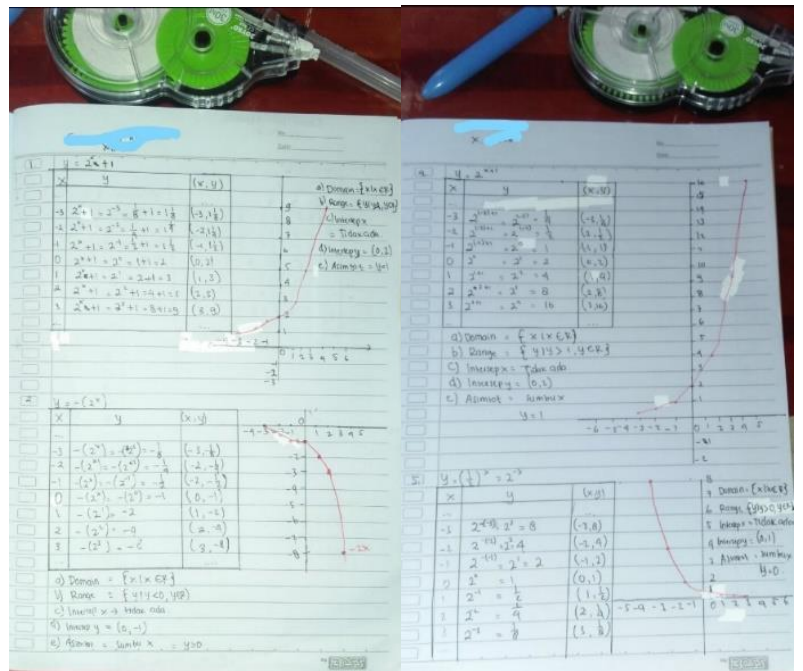

Figure 3. Student's work on a task.

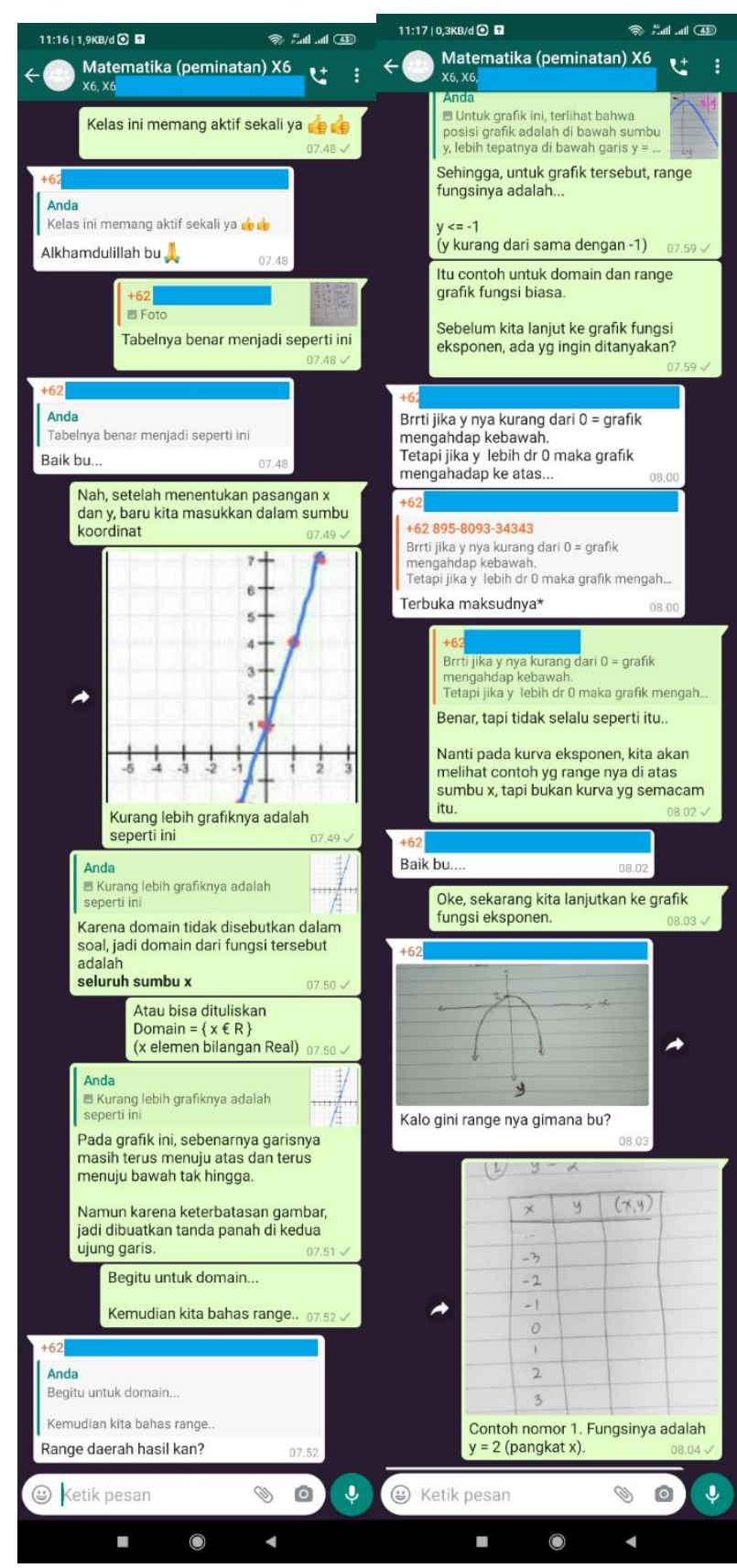

Figure 1. Active Discussion via WhatsApp Group.

\section{CONCLUSION}

Flipped classroom design is very useful for learning, as it focuses on students' learning independence and collaboration. However, the design is also prone to challenges, especially in terms of the technological awareness of both the teachers and the students. When educators decided to use a flipped classroom, they have to consider essential elements of the course design such as conducting needs assessments, determining content and learning outcomes, and selecting appropriate educational and assessment methods [15]. To learn more about the idea of flipped classroom design, teachers 
should enhance their knowledge through training or collaborative study with professionals or experts in the flipped classroom. This is vital because it helps the teacher set up their classroom properly. The teacher also should understand the possibilities where a student is not engaging with the flipped classroom and try to encourage them with several treatments such as assessments and quizzes, and also by imposing leader group rotation to ensure all students equally participate.

To conduct learning in the pandemic era which has to be fully online learning, teachers have to be creative and wise in considering students' conditions. Teachers have to adopt the flipped classroom learning and optimize the provided facilities in order to have the best results in the learning. Carefully choosing the platforms which are accessible to the students is one of the keys to successfully conduct flipped classroom in the pandemic era.

\section{ACKNOWLEDGMENTS}

The authors would thank SMAN 1 Slawi for their contributions to this research.

\section{REFERENCES}

[1] Ash K 2012 Educators evaluate flipped classrooms Education Week pp 1-5.

[2] Barrack L 2016 Educators: blended learning key: schools are integrating digital tools to ready students for college School Library Journal vol 62(2) p 18

[3] Bishop L J and Verleger M 2013 The Flipped Classroom: A Survey of the Research Proceedings of the Annual Conference of the American Society for Engineering Education p 6219

[4] Dahdal S 2020 Using the WhatsApp Social Media Application for Active Learning 2020 Journal of Educational Technology Systems vol 0(0) p 1

[5] Dündar S 2016 Does Writing Have Any Effect on Mathematics Success? Journal of Education and Training Studies vol 4(1) pp 1-10

[6] Fulton K 2012 Upside down and inside out: Flip your classroom to improve student learning Learning \& Leading with Technology vol 39(8) pp 12-17

[7] Hamdan $\mathrm{N}$ McKnight $\mathrm{P}$ McKnight $\mathrm{K}$ and Arfstrom K M 2013 A review of flipped learning Flipped Learning Network p 20.

[8] Herreid C and Schiller N 2013 Case studies and the flipped classroom Journal of College Science Teaching vol 42(5) pp 62-66

[9] Kensington-Miller B Novak J and Evans T 2016 Just do it: Flipped lecture, determinants and debate International Journal of Mathematical Education in Science and Technology pp 1-10.

[10] Kirvan R Rakes R C and Zamora R 2015 Flipping an algebra classroom: Analyzing, modeling, and solving systems of linear equations Computers in The Schools vol 32(3-4) pp 201-223.

[11] Love B Hodge A Grandgenett N and Swift A W 2013 Student learning and perceptions in a flipped linear algebra course International Journal of Mathematical Education in Science and Technology vol 45(3) pp 317-324.

[12] Marco F A Penichet V M R and Lazaro J A G 2013 Drawer: An innoative teaching method for blended learning In Proceedings of the 2013 federated conference on computer science and information systems pp 727-734

[13] Marshall H W 2013 Three reasons to flip your classroom

[14] Mcclelland C J 2015 Evaluating the effect of thoughtful design of in-class time for a flipped classroom IEEE Frontiers in Education Conference (FIE) pp 725-728.

[15] Moffett J 2015 Twelve tips for "flipping" the classroom Medical Teacher vol 37(4) pp 331-6.

[16] Moore A J Gillet M R and Stelee M D 2014 Fostering student engagement with the flip The Mathematics Teacher vol 107(6) pp 420-425.

[17] Muir T and Geiger V 2015 The affordances of using a flipped classroom approach in the teaching of mathematics: a case study of a grade 10 mathematics class Mathematics Education Research Journal vol 28 pp 149-171

[18] Ng W 2014 Flipping the science classroom: Exploring merits, issues and pedagogy Teaching Science vol 60(3) pp 16-27

[19] Petrillo J 2015 On flipping first-semester calculus: a case study International Journal of Mathematical Education in Science and Technology pp 1-10

[20] Roach T 2014 Student perceptions toward flipped learning: New methods to increase interaction and active learning in economics International Review of Economics Education vol 17 pp 74-84.

[21] Ryan M D and Reid S A 2015 Impact of the Flipped Classroom on Student Performance and Retention: A Parallel Controlled Study in General Chemistry J. Chem. Educ. vol 93 pp 13-23

[22] Saurabh S and Gautam S 2019 Modelling and statistical analysis of YouTube's educational videos: A channel Owner's perspective Computers \& Education vol 128 pp 145-158.

[23] Shakoor M 2011 On Becoming a Group Member: Personal Growth and Effectiveness in Group Counseling (New York: Routledge Taylor and Francis Group).

[24] Strayer J F 2012 How learning in an inverted classroom influences cooperation, innovation and task orientation Learning Environments Research vol 15(2) pp 171-193.

[25] Van Seters J R Ossevoort M A Tramper J and Goedhart M J 2012 The influence of student characteristics on the use of adaptive e-learning material Computers and Education vol 58(3) pp 942-952. 
[26] Wilder S 2015 Classroom Challenge: A 3D Snapshot of Student Learning in Mathematics The Clearing House: A Journal of Educational Strategies, Issues and Ideas vol 88(3) pp 77-84.

[27] Wilson S G 2013 The Flipped Class: A Method to Address the Challenges of an Undergraduate Statistics Course Teaching of Psychology vol 40(3) pp 193-199.

[28] Yamaguchi R 2001 Children's learning groups: A study of emergent leadership, dominance, and group effectiveness Small Group Research vol 32(6) pp 671-697. 